\title{
Promoção da Saúde e Medicalização: Notas Inquietantes em Conversas de Foucault com Canguilhem ${ }^{1}$
}

\section{Health Promotion And Medicalization: Disturbing Notes In Talk Of Foucault With Canguilhem}

\author{
BRUNO JAY MERCÊS DE LIMA \\ Doutor em Psicologia (UFPA). Professor no Centro Universitário Metropolitano da \\ Amazônia(UNIFAMAZ) \\ bruno_lima@ @hotmail.com \\ DAIANE GASPARETTO DA SILVA \\ Professora do Departamento de Psicologia da Universidade do Estado do Pará e como \\ Psicóloga/Técnica em Gestão Penitenciária do Estado do Pará (SEAP) \\ dai_gasparetto@hotmail.com \\ FLÁVIA CRISTINA SILVEIRA LEMOS \\ Professora associada III, na Graduação e no Programa de Pós-graduação em \\ Psicologia/UFPA. \\ flaviacslemos@gmail.com
}

\section{RESUMO}

Este artigo visa problematizar práticas de promoção de saúde no Brasil, a partir da história da saúde pública no país, em uma analítica da medicalização e da gestão higienista do hospital, da cidade, dos pobres e do Estado. Busca-se pensar como emerge junto com a saúde na atenção básica um modo de gerir a política pública de saúde como tática medicalizante dos corpos, do espaço, do hospital, da comunidade e das relações sociais. Interroga-se no seguinte ensaio temático um conjunto de práticas que operam um mecanismo biopolítico e de governo da vida e das existências por meio de intensa medicalização na atuação preventivista da saúde. Portanto, questiona-se o estilo de vida saudável na sociedade contemporânea a partir de uma estratégia medicalizadora do direito à saúde com Michel Foucault e Georges Canguilhem.

Palavras-chave: Saúde. Medicalização. Práticas. Biopolítica. Prevenção.

\section{ABSTRACT}

This article aims to problematize health promotion practices in Brazil, based on the history of public health in the country, in an analysis of medicalization and hygienist management of the hospital, the city, the poor and the State. It seeks to think about how a way to manage public health policy emerges together with health in primary care as a medicalizing tactic of bodies, space, hospital, community and social relations. in the following thematic essay a set of practices that operate a biopolitical and government mechanism of life and existences through intense medicalization in preventative health

\footnotetext{
${ }^{1}$ Artigo submetido para avaliação em 25 de outubro de 2021 e aprovado em 12 de novembro em 2021.
} 
Rev. Interd. em Cult. e Soc. (RICS), São Luís, v. 7, n. 2, p. 114- 135, jul./dez. 2021

ISSN eletrônico: 2447-6498

action. Therefore, the healthy lifestyle in contemporary society is questioned based on a medicalizing strategy of the right to health.

Keywords: Health. Medicalization. Practices. Biopolitics. Prevention.

\section{INTRODUÇÃO}

O objetivo deste artigo é pensar as práticas de medicalização e patologização da vida em uma conversa com Michel Foucault e Georges Canguilhem, em um ensaio temático, fruto de diversos trabalhos que temos realizado com estudos a respeito da patologização e medicalização da existência, dos corpos, da saúde e da educação. Busca-se interrogar modos de objetivar a saúde e o cuidado agenciados à racionalidade biomédica e psicologizante das subjetividades.

Para compreendermos a constituição da medicalização na Atenção Básica no Brasil, precisamos recorrer à História para vislumbrarmos o surgimento da preocupação com/atenção à saúde no mundo ocidental, principalmente sobre as populações, assim como, a posteriori, no Brasil. Não há aqui qualquer pretensão de estabelecer, já sinalizado por Foucault (2013), uma sistematização dos acontecimentos a fim de encaixá-los em totalidades: o autor nos mostra que a história tem como marcas as descontinuidades, rupturas, continuidades, que mostram o caráter de movimentação de diversos poderes que impactam no surgimento das práticas de saúde, no caso desta pesquisa. Com este capítulo, pretendo denotar os problemas de saúde encontrados na história, a partir do século XVI no Ocidente, e que fizeram emergir as políticas de atenção à saúde e a consequente medicalização da vida das populações.

A preocupação com a saúde não é algo de agora. Desde Hipócrates, diversos pensadores, filósofos, cientistas, tem se debruçado para pensar formas de intervir sobre moléstias. Até mesmo se considerarmos o nível coletivo, já existiam, na Grécia Antiga, escritos demonstrando que algumas ideias sobre as origens e transmissões das enfermidades explicavam que estas se davam pelo ar, pela água ou mesmo pela composição líquida presente nos corpos, denotando os quatro humores - linfa, fleuma, bile amarela, bile negra (ESCOREL et al, 2015).

Todavia, a medicina exercida até, pelo menos, o século XVI, era estritamente individualista. Essa configuração começa a se modificar somente a partir da entrada da medicina no hospital. Foucault (2013), em O Nascimento do Hospital, nos revela que 
Rev. Interd. em Cult. e Soc. (RICS), São Luís, v. 7, n. 2, p. 114- 135, jul./dez. 2021

ISSN eletrônico: $2447-6498$

esta instituição, como espaço de saúde, é uma novidade somente no século XVIII. Até então, este espaço possuía uma única finalidade: salvar as almas que estavam em sofrimento. Servia, por um lado, para salvar as almas daqueles que cuidavam, diminuindo sofrimento, acalantando, acompanhando o sofrimento, e daqueles que eram cuidados. Por isso que se entendia o hospital como um morredouro, onde se dava assistência material e espiritual para conseguir a salvação eterna. Então, alinhava-se a função de garantir a paz pós-morte à necessidade de função de separar as pessoas que ofereciam algum tipo risco para a população. Não se percebe, logo, nenhuma alusão ao personagem médico neste espaço.

O hospital como instrumento terapêutico é uma invenção relativamente nova,
que data do final do século XVIII. A consciência de que o hospital pode e
deve ser um instrumento destinado a curar aparece claramente em torno de
1780 [...]. O hospital que funcionava na Europa desde a Idade Média não era,
de modo algum, um meio de cura, não era concebido para curar. Houve, de
fato, na história dos cuidados no Ocidente, duas séries não superpostas;
encontravam-se às vezes, mas eram fundamentalmente distintas: as séries
médica e hospitalar. O hospital como instituição importante e mesmo
essencial para a vida urbana do Ocidente, desde a Idade Média não é uma
instituição médica, e a medicina é, nesta época, uma prática não hospitalar
(FOUCAULT, 2013, p. 171).

O médico, então, somente aparecia nos espaços abastados. Era uma medicina de família, em que um médico acompanhava gerações de um mesmo grupo familiar, exercendo uma medicina voltada para o ambiente privado. $\mathrm{O}$ ambiente hospitalar nem mesmo fazia parte da formação em medicina, pois bastava ao sujeito passar por uma formação que assegurava o conhecimento sobre textos específicos, assim como a transmissão deste em forma de receitas, que lhe era garantida tal possibilidade de atuação e não a sua experiência. Somente ao passo que o hospital passa a se tornar um problema, passar a ter efeitos negativos, a ser uma ameaça para o espaço da cidade em crescimento (principalmente a partir das atividades comerciais, atraindo mais e mais pessoas, por consequência, gerando mais e mais doentes devido às condições sanitárias), que formas de intervenção sobre o hospital são produzidas. Inicialmente, essa preocupação se deu sobre os hospitais marítimos, uma vez que era comum o comércio ilegal de especiarias, objetos valiosos, feitos por marítimos que fingiam ou estavam doentes, facilitando, assim, a esquiva das barreiras alfandegárias (FOUCAULT, 2013).

O controle sobre o hospital marítimo era muito mais econômico do que de saúde: visava diminuir as fugas de patrimônio e isso ocorre (tal controle) porque é neste 
Rev. Interd. em Cult. e Soc. (RICS), São Luís, v. 7, n. 2, p. 114- 135, jul./dez. 2021

ISSN eletrônico: $2447-6498$

momento que há um aumento de regulamentações econômicas no mercantilismo. Além disso, com o avanço das tecnologias de navegação e o próprio trabalho exercido nos espaços da marinha e do exército (específicos e com necessidade de investimento para sua qualificação), emerge a necessidade de se controlar a saúde destes militares: o custo alto para a formação de uma mão de obra tão especializada como a deles, em conjunto com a necessidade de manter as suas vidas, fazem do espaço militar a predileção para o surgimento da disciplina. Disciplina, conforme Foucault (2013, p. 181), “[...] é análise do espaço. É a individualização pelo espaço, a inserção de corpos em um espaço individualizado, classificatório, combinatório". A disciplina tem como característica o controle sobre o desenvolvimento de um processo, uma tarefa, acompanhado, consequentemente, por uma vigilância constante dos sujeitos, através dos registros, relatórios, documentos que sinalizam e captam informações desse processo, é um conjunto de técnicas que o poder terá o indivíduo como alvo e resultado, é uma forma de individualização.

\section{HOSPITAL MEDICALIZADO, PATOLOGIZAÇÃ̃ E SAÚDE}

Podemos elencar, então, os três motivos pelos quais o hospital passa a ser medicalizado: as razões econômicas listadas (a necessidade de controle sobre o tráfico que ocorria nos espaços marítimos), o valor de cada sujeito militar (que dispendia investimento para garantir uma qualificação do seu trabalho e evitar seu adoecimento e morte) e a propagação de doenças advindas destes espaços. O médico adentra ao espaço hospitalar como disciplinador. É ele quem irá transformar o ambiente em que o doente é colocado, atentando para o distanciamento entre as pessoas, com uma disposição que facilite a vigilância sobre estas e com o registro como fonte de informações para a perpetuação desse controle. Somente assim é que o hospital passa a ter caráter terapêutico: surge a necessidade de controlar até mesmo a localização do hospital em relação à cidade, a fim de dificultar as pandemias, e a sua própria disposição espacial interna (FOUCAULT, 2013).

A partir da sua entrada no hospital, influenciando na organização espacial, na disposição dos doentes, na arquitetura, aquisição de materiais, dentre outras tarefas, o médico, aos poucos, vai tomando para si as responsabilidades que antes pertenciam aos religiosos. A tarefa de pensar a organização da instituição, as questões financeiras, administrativas, passam a ter respaldo do saber médico (tendo como embasamento as 
Rev. Interd. em Cult. e Soc. (RICS), São Luís, v. 7, n. 2, p. 114- 135, jul./dez. 2021

ISSN eletrônico: 2447-6498

diversas informações que estão agora documentadas, dando sustentação científica para a tomada de decisões). Este personagem novo do hospital garante tanto poder a si que, na segunda metade do século XVIII, passa a ser o responsável pela organização hospitalar. As visitas aos doentes devem ser mais frequentes, a estadia do médico neste espaço deve ser ostensiva, pois o médico agora é indispensável ao hospital e, garantido pelo registro permanente do que acontece, os documentos passam a servir, para além do controle, também para a expansão do saber médico (os registros permitem a análise, comparações, verificações de procedimentos e comparações com outros dados coletados em outros hospitais, é a constituição da clínica).

Concomitantemente, a partir do século XVI e XVII, com o crescimento abrupto de epidemias em um curto espaço de tempo e em locais populosos, diferentemente do que já se tinha visto até então, ocorre um consequente aumento da preocupação com a situação da saúde das populações. As epidemias se tornam um problema de Estado quando, ao afetar o crescente comércio mercantilista, passam a impactar sobre as riquezas, sobre o trabalho. O Estado, então, passa a ser cobrado por uma atuação de controle sobre as doenças, pela primeira vez, antes de acontecerem (FOUCAULT, 2013).

Um conjunto de métodos de análises, estatísticas, cálculos de probabilidades entram em jogo para garantir o governo da saúde através de números. Porém, a atuação do Estado não se resumiu à constatação dos números: já no século XVIII, emergem também um conjunto de políticas, instituições, espaços, que vão consolidar no Ocidente a crença de que os governos deveriam usar de força política para garantir que a população fosse melhor controlada quanto à saúde.

Países europeus começam a mudar suas ações frente às necessidades de saúde, principalmente por estarem agora no crescente processo de industrialização. Na Alemanha, surge o sistema de polícia médica, uma forma centralizada de elaboração e implementação de ações sanitárias, passando a destacar a figura do médico como principal realizador. Estas ações visavam dirigir aspectos relacionados à alimentação, saúde pública em geral e até à gestação, além de atenção às doenças endêmicas. Percebe-se, então, a emergência de uma medicina voltada ao corpo social. Foucault (2013, p. 158) explica: 
Rev. Interd. em Cult. e Soc. (RICS), São Luís, v. 7, n. 2, p. 114- 135, jul./dez. 2021

ISSN eletrônico: $2447-6498$

desenvolvendo-se em fins do século XVIII e início do século XIX, socializou um primeiro objeto que foi o corpo enquanto força de produção, força de trabalho [...]. Foi no biológico, no somático, no corporal que, antes de tudo, investiu a sociedade capitalista.

Já, na França, também influenciada pelas mudanças ocorrendo nos outros países europeus no que tange à questão da saúde, enfrentando problemas semelhantes, a medicina social surge a partir da preocupação com o espaço urbano. Diferentemente do que ocorria na Alemanha, a medicina social francesa desenvolve, a partir da racionalidade científica do momento, normas de convivência das pessoas em espaços urbanos: desde espaços abertos, como praças e parques, passando pelas escolas, deveriam ser propagadas as normativas para garantir a proteção frente ao perigo do que significa o espaço aberto/público/coletivo.

O higienismo, impulsionado pela reconfiguração do espaço urbano a partir da industrialização, consagrava os determinantes para as condições sanitárias das pessoas nos espaços urbanos. Para além disso, muitos destes saberes adentram o espaço privado da família. Donzelot (1980) vai mostrar que a medicina exercida sobre a família possuía aspecto muito mais moralizante que de saúde: a mãe deveria executar um conjunto de ações para garantir a sobrevida das crianças e, sob esta prerrogativa, desenvolvia-se recomendações sobre a vida dos pobres, mascaradas com valores morais burgueses em ascensão.

E, na Inglaterra, conforme Foucault (2013), era uma medicina do trabalho que surgia as condições de vida da população mais pobre colocavam em risco o desenvolvimento do capitalismo crescente, pois as pessoas viviam em espaços altamente amontoados, em cortiços perigosos à saúde, que não disponibilizavam de condições para a manutenção da saúde para o trabalho. Além disso, a manutenção dessa situação também caracterizava risco à saúde da burguesia, que estava em contato, de alguma forma, com essa maior parcela da população, seja na rua, espaços coletivos ou no ambiente de trabalho. Aos poucos, diversas diretrizes foram se desenvolvendo, versando sobre as condições de vida das pessoas, como também sobre a necessidade de esgotamento, destinação de lixos e fezes, água potável para a população e ações de engenharia. Estes dois processos destacados (a entrada da medicina no espaço hospitalar e o surgimento da medicina social), em conjunto com a clínica (que se organizou como um poder médico a partir de um conjunto de saberes, anatomia, fisiologia, patologia, por exemplo), possibilitaram a 
Rev. Interd. em Cult. e Soc. (RICS), São Luís, v. 7, n. 2, p. 114- 135, jul./dez. 2021

ISSN eletrônico: $2447-6498$

[...] disciplinarização do espaço médico, pelo fato de se poder isolar cada indivíduo, colocá-lo em um leito, prescrever-lhe um regime, etc., pretende-se chegar a uma medicina individualizante. Efetivamente, é o indivíduo que será observado, seguido, conhecido e curado. O indivíduo emerge como objeto do saber e da prática médicos. Mas, ao mesmo tempo, pelo mesmo sistema do espaço hospitalar disciplinado se pode observar grande quantidade de indivíduos. Os registros obtidos quotidianamente, quando confrontados entre os hospitais e nas diversas regiões, permitem constatar os fenômenos patológicos comuns a toda a população (FOUCAULT, 2013, p. 176).

A incorporação dos saberes advindos da biologia com a descoberta da relação entre bactéria e doença, constituiu as bases para uma medicina cientifica com a determinação do patógeno e, por consequência, da observação, do diagnóstico e do tratamento a ser usado. A saúde pública se torna, assim, uma ciência, mas também uma forma de intervenção política sobre as populações, consolidando-se como uma medicina individual e social, ao mesmo tempo. Porém, este mesmo saber, também consolidou o higienismo como uma forma de controlar a vida das pessoas, pois retirou de foco as condições de vida destas e passou a se basear somente na bacteriologia para o desenvolvimento de suas formas de intervenção, restringindo-se à análise biológica do problema. É justamente esta limitação intencional que, a partir do século XX, passa a fundamentar a disciplinarização das pessoas e a medicalização da vida, fazendo com o que o indivíduo, isoladamente, passasse a ser o único responsável pela sua saúde. A saúde pública nasce, assim, a partir da biopolítica das populações (FOUCAULT, 2013).

No bojo desta discussão, Canguilhem possibilita pensarmos que a patologia não é uma variação quantitativa do normal. Esta afirmação abre um campo de análises constitutivas de uma atitude crítica face às práticas sociais, econômicas, políticas, culturais, biológicas, médicas, jurídicas e psicológicas que operam agenciamentos medicalizantes, a partir da relação entre normal e anormal.

O anormal só poderia surgir como oposição ao normal enquanto negação deste, na medida em que traçando um quadro normativo da vida, os fatos passam a ser classificados como tentativas de controle do corpo orgânico e da sociedade definida pela metáfora de um organismo social. As normas na patologização são retiradas dos contextos que as constituem e entram em um regime de relações que as naturalizam e as reduzem de forma positivista a variações de um organismo funcionalizado por cálculos estatísticos produtivos de modelos, distribuídos em uma curva da Gauss (CANGUILHEM, 1995). 
Rev. Interd. em Cult. e Soc. (RICS), São Luís, v. 7, n. 2, p. 114- 135, jul./dez. 2021 ISSN eletrônico: $2447-6498$

Ora, desta maneira, a patologia não pode decorrer da ausência de saúde e ser deduzida como uma analogia ou lógica de pólos opostos. Contudo, a patologia não é o oposto à saúde, mas parte desta experiência. Portanto, a saúde não é um modo momentâneo de produzir a norma, pois pode ultrapassar o campo de uma determinada norma e do seu negativo. A apreciação de um fato e/ou de um acontecimento implica uma construção de julgamento deste a partir de uma prática baseada na normatividade vital enquanto história conceitual, pois, a vida e a saúde são construídas no plano dos valores e modos de avaliar a existência por meio do regramento das relações no bojo deste processo normativo (CANGUILHEM, 1995).

Um exemplo desta construção normativa é a localização do cérebro como uma máquina semelhante a um computador e como um depósito neuroquímico. Se prescinde da vontade e das lutas político-sociais em prol de uma visão de cérebro-máquina eletrônica a ser concertada e regulada como biologia de ajustes técnicos. A promoção de saúde pode ser importante para interrogarmos estas lógicas, porém, pode ainda ser cooptada e instrumentalizada no âmbito dos processos vitais como ortopedia do cuidado por mediações de uma economia comportamental e de uma gestão de riscos, pautada no cálculo das normas por modelos de controle social em modulações estatísticas e epidemiológicas (CANGUILHEM, 1993).

A gramática da doença não é natural nem existe como uma antecipação, ela é construída por práticas de objetivação. Valoração é um processo de atribuição de sentido e da realização de julgamentos, implica classificar e definir, categorizar e adjetivar experiências por meio da mediação de normas e leis, em um plano de produção de saúde como singularidade e perspectivismo sociocultural.

\section{DA SAÚDE DAS POPULAÇÕES COMO PROBLEMA INTERNACIONAL}

Anteriormente, vimos os passos que foram traçados na história para tornar espaços e questões em focos de intervenções médicas. Esse processo possibilitou o surgimento do poder médico, enquanto uma força disciplinadora de corpos e espaços, assim como a emergência de um campo do saber (a medicina), atravessado por diversos outros, principalmente advindos da biologia, anatomia, fisiologia e patologia, que se utiliza de diversos instrumentais (os documentos, a clínica, a estatística) para expandir ainda mais seu saber e fortalecer o poder constituído (FOUCAULT, 2017). Destarte, veremos, então, que este emaranhado de saber/poder não se limitou aos países 
Rev. Interd. em Cult. e Soc. (RICS), São Luís, v. 7, n. 2, p. 114- 135, jul./dez. 2021

ISSN eletrônico: $2447-6498$

analisados: a preocupação se expandiu e o que era antes algo restrito ao país, agora se torna um problema de saúde global.

As necessidades de expansão das atividades econômicas, novamente, dessa vez impulsionada pelo avanço da industrialização, foi a principal motivação para a articulação entre Estados para uma nova organização: o aumento das zonas de comércios (impactando na reorganização das cidades com aumento populacional) coadunado à preocupação crescente com as epidemias (para que não interfiram nas atividades econômicas), fizeram com que os países estabelecessem acordos de cooperação. Essas iniciativas se iniciam no continente americano, com a criação da Organização Panamericana de Saúde (OPAS), sendo a primeira instituição internacional a ser criada com a finalidade de desenvolver políticas voltadas para a saúde da população, em 1902. Os Estados Unidos da América (EUA), considerando a expansão do capitalismo, foi o principal articulador para tal organização surgir: desenvolveu influência maciça sobre países, principalmente latino-americanos, para a organização dos serviços de saúde tendo como referência o seu sistema. Passou, então, a ser da ordem do dia a construção de agendas em conjunto e a interação entre especialistas dos países envolvidos (ROSEN, 1994).

Com o avanço de suas atividades, a OPAS passa a desenvolver mais acordos: tais poderiam agora influenciar não somente práticas para o controle de pandemias ou doenças emergentes, como também a própria organização da estrutural gerencial e laboral dos aparatos de Estado presentes em cada país. Além de ações para estes fins, a OPAS também passa a desenvolver acordos sobre enfermagem, bolsas de pesquisas, saneamento, dentre outros. Especificamente sobre as bolsas, vale dizer que instituições como a Fundação Rockfeller passam a investir no aumento de ofertas, formando profissionais de saúde dentro da lógica flexneriana (de Abraham Flexner, que defendia que a formação em saúde deveria estar pautada nos diagnósticos para produção de intervenção; retirando, assim, os aspectos sociais do processo saúde-doença da análise, até indicando que instituições que os considerasse não deveria receber recursos). Percebemos, assim, a intencionalidade em desenvolver uma atenção e concepção de saúde dentro de uma lógica de saber, pautado principalmente no positivismo (LIMA et al, 2005). 
Rev. Interd. em Cult. e Soc. (RICS), São Luís, v. 7, n. 2, p. 114- 135, jul./dez. 2021

ISSN eletrônico: $2447-6498$

A Organização das Nações Unidas (ONU) só surge em 1945, após a II Guerra Mundial, com o objetivo de estabelecer a paz e cooperações das mais variadas entre as nações "vencedoras" da Guerra. Agora com a possibilidade da expansão do saber tradicional em saúde (que pensa o ser humano saudável como aquele que não possui doenças, vistas como um empecilho para o desenvolvimento econômico das nações), seguindo as orientações da já existente OPAS, farias cooperações em torno da saúde foram estabelecidas, nesse momento, capitaneadas pela principal agência em saúde do mundo, pertencente à ONU: a Organização Mundial da Saúde (OMS). Criada em 1948, a OMS possui a responsabilidade de encaminhar tratados e acordos políticos referentes à saúde das populações dos países componentes (LIMA et al, 2005).

O conceito clássico de saúde enquanto "mais completo estado físico, mental e social e não apenas ausência de doenças e enfermidades" da OMS explicita, então, que a compreensão da saúde é ampla para a organização, e que seus serviços em cada país devem funcionar de modo articulado a outras áreas de desenvolvimento social. Para muitos, esta compreensão é utópica e sem respaldo científico, pois não atende os critérios de cientificidade a partir do saber hegemônico, principalmente o defendido pelos EUA e OPAS.

Surge, então, o Welfare State, onde a saúde passa a ser atrelada aos sistemas previdenciários dos países, principalmente EUA e Inglaterra que logo aderiram, para consolidar a responsabilidade da saúde como função do Estado. O trabalho sendo fator central de desenvolvimento econômico das nações, no pós-guerra, e as diretrizes emanadas dos órgãos ONU e OMS, encontram na centralidade do Estado a correia para a expansão do modo de governo da saúde. Enquanto no EUA havia o documento norteador Relatório Flexner, na Inglaterra, o plano Beveridge, serviam de norteadores para o desenvolvimento de tais políticas (LIMA et al, 2005).

Já na segunda metade do século XX, a OMS não se preocupa tanto com os serviços privados de saúde e previdência: é para os serviços públicos dos países associados que sua atenção se volta, principalmente para aqueles em que a industrialização avançava (como o Brasil), impulsionada essa atenção devido ao aumento das especializações médicas dentro dos serviços previdenciários. Recebendo grandes quantias de recursos da Fundação Rockfeller, a OMS se responsabiliza pela formação de profissionais de saúde nos países, intervindo em currículos e espaços de intervenção, porém, era diversos e adversos os interesses que deveriam ser conciliados 
Rev. Interd. em Cult. e Soc. (RICS), São Luís, v. 7, n. 2, p. 114- 135, jul./dez. 2021

ISSN eletrônico: $2447-6498$

neste cenário. De um lado, havia o interesse daqueles que queriam garantir a atenção à saúde às populações, e de outro lado, aqueles que estavam mais preocupados em como gerar lucro a partir das mudanças nos serviços de saúde, como a indústria farmacêutica, que já por volta de 1950 apresentava expansão franca, o que não poderiam fazer era deixá-la de fora sem atender seus interesses (MOREIRA et al, 2016).

Nesse cenário, impulsionado pela "crise da medicina científica" e a necessidade de se alcançar saúde de qualidade através da organização dos sistemas de saúde nos países, já na segunda metade do século XX, o preventivismo se apresenta como uma possibilidade de reorientação das ações em saúde, assim como da natureza dos serviços encontrados, além da constituição de outros novos. Essa mudança de paradigma foi encabeçada pela OPAS dentro da OMS (já a partir de 1950) como um movimento internacional para defesa da medicina integral (desde o período demarcado, a OPAS já apresentava documentos que direcionavam para essa nova proposta em saúde). Essa proposta compreendia a saúde num direcionamento distinto da medicina científica: segundo Arouca (2003), a medicina preventiva foi uma mudança na educação em saúde, sem avanços em conhecimentos e demais áreas a priori, muito mais pautada numa mudança de postura médica, na forma de desenvolver a relação com os pacientes, familiares e comunidade. A doença passa a ser uma característica frente à totalidade da vida da pessoa em cuidado (MOREIRA et al, 2016). Entretanto, a centralidade da doença permanece:

\footnotetext{
A medicina preventiva manteve-se centrada na doença, sendo a integração pretendida com a comunidade baseada em esquemas artificiais, impondo um nível de medicalização científica e, ao mesmo tempo, político, na geração da expectativa de superar dificuldades de várias naturezas em espaços sociais (LOPES, 2012, p. 66).
}

Não queremos dizer, de modo algum, que a medicina preventiva não tenha contribuído para a organização e reorientação dos serviços de saúde. Não podemos desconsiderar que tais ideias nascentes impactaram sobre a constituição dos níveis de prevenção em saúde, a saber, primário, secundário e terciário, guardadas suas características que apresentaremos mais a frente, influenciadas pelo modelo de história natural da doença de Leavell e Clark (AROUCA, 2003). Na compreensão destes estudiosos, a saúde estava dependente dos três agentes envolvidos no processo saúdedoença: o hospedeiro, o agente patogênico e a ambiente. Apesar de se considerar os 
Rev. Interd. em Cult. e Soc. (RICS), São Luís, v. 7, n. 2, p. 114- 135, jul./dez. 2021

ISSN eletrônico: $2447-6498$

aspectos sociais como importantes neste processo, não há uma especificação da amplitude destes aspectos, o que acaba esvaziando a importância pretendida. O que essa reorientação faz é, de modo efetivo, fazer com que as pessoas considerem que fatores como rotina, qualidade de vida, bons hábitos alimentares, sejam considerados, porém, como ações individuais de cuidados em saúde: vemos aqui, então, um avanço da medicalização a partir de uma teoria que pretendia diminuir a centralidade da doença, do diagnóstico e da atuação medicalizante (LOPES, 2012).

Para além do observado, o que o preventivismo gerou aumento da compreensão da saúde enquanto ausência de doenças, instalando uma vigilância das pessoas sobre seus próprios corpos, passando a considerar-se como portadoras de possíveis doenças desconhecidas e somente acessíveis com as novas tecnologias diagnósticas. Já não vemos aqui somente um poder que atua sobre o corpo dos sujeitos, passa-se a perceber que as ações possuem impacto também sobre a subjetividade, responsabilizando cada pessoa sobre sua própria saúde, ainda que se considere, parcamente, os fatores sociais e econômicos para sua melhor compreensão. O que deveria ser um saber de contraposição ao hegemônico anterior (mas ainda vigente na atualidade), torna-se espaço necessário para a expansão da perspectiva individualizante do atendimento em saúde, assim como favorece à indústria farmacêutica (também chamada de bigpharma) crescer em meio a esse emaranhado que ainda se reorganiza nos países latino-americanos, principalmente (ESCOREL et al, 2015).

A noção de risco, como apresentada por Castel (1987), passa a ser palavra de ordem nos serviços de saúde (principalmente na saúde mental, como explicitado pelo autor) e corrobora com a medicalização induzida pelas mudanças de funcionamento e orientação dos serviços de saúde. Os médicos, além de realizar diagnóstico e tratamento, também irão intervir sobre os riscos: fatores presentes nas vidas das pessoas que podem contribuir para o aparecimento de algum diagnóstico no seu corpo. Percebemos aqui, que a ampliação da intervenção médica para o campo dos "riscos" abre possibilidades de interferência sobre outros aspectos da vida humana, inclusive os sociais que foram considerados como fatores importantes para a saúde da população, ainda que sem muita delimitação sobre seus significados reais.

A concepção preventivista de saúde, agora contemplada pela compreensão de risco, trouxe novas "armadilhas" para o entendimento do que é saúde: o risco faz com 
Rev. Interd. em Cult. e Soc. (RICS), São Luís, v. 7, n. 2, p. 114- 135, jul./dez. 2021

ISSN eletrônico: 2447-6498

que haja uma ampliação sobre o que seria o escopo de atuação da saúde e foca nos riscos individuais. Há, assim, um aumento sobre a percepção de saúde enquanto individual, enquanto fruto de atuação do sujeito e dependente somente deste para manter qualidade. A epidemiologia, já no final do século XX, tendo o status de referência para políticas de saúde, passa a focar nos números de adoecimento e nas condições que facilitam o adoecimento. Mas passam a desconsiderar os fatores concretos e cotidianos que possam ser modificados para evitar o adoecimento. $\mathrm{O}$ foco no individuo se faz na intervenção sobre o estilo de vida, alimentação e outros que possuem, na estatística, relação com morbimortalidades (CAPONI, 2007).

\footnotetext{
A ideia de saúde, sob a égide da crítica da perspectiva de risco, seria a abertura ao risco. E, nessa direção, não poderia ser objetivo da saúde pública o de buscar a saúde perfeita, mas a potencialização da visibilidade do que seja risco em toda a sua amplitude, e não apenas em algumas de suas esferas, o que desviaria ações em saúde com caráter fragmentado, totalizado e disciplinarizador de sujeitos (LOPES, 2012, p. 68).
}

Partindo, então, de uma compreensão crítica ao modelo preventivista de saúde, a saúde passaria a ser entendida como resultante de condições de vida coletivas da população, que possibilitassem as mais diversas formas de existências e não as suas limitações. A população passaria a compreender a saúde para além do mal-estar causado no corpo, de forma abstrata, como o anormal a ser combatido. Saúde então, passaria a ser entendida como um espaço de tensão nas políticas públicas, uma vez que se evidencia a limitação da atuação do preventivismo, pois limita as possibilidades de ampliação de práticas de saúde (LOPES, 2012).

Portanto, qualquer compreensão de saúde que emerja num cenário específico, representará a busca por definição de conceitos e parâmetros que são frutos dos tensionamentos locais sobre a ideia em crise, em disputa. O Estado passa a ser o intermediador destes conceitos e parâmetros, que assume a responsabilidade por estatizar a saúde e pela manutenção da vida dos sujeitos, atuando como balizador, então, sobre o significado de saúde. Porém, a natureza complexa da saúde faz com que as formas de conceituação sejam, em algum momento ou perspectiva de análise, limitadas: não se pode constituir, então, um conceito pleno e organizado, final, sobre saúde. Suas características abarcam fatores que extrapolam a própria figura do Estado, por representarem possibilidades de existência frente a uma figura que tenta limitá-la.

\section{DA PROMOÇÃO DA SAÚDE COMO AMPLIAÇÃO DA MEDICALIZAÇÃO}


Rev. Interd. em Cult. e Soc. (RICS), São Luís, v. 7, n. 2, p. 114- 135, jul./dez. 2021 ISSN eletrônico: $2447-6498$

Como já demonstrado, as ideias que estavam vigentes do preventivismo não estavam dando conta de explicar e/ou resolver as complexidades dos problemas de saúde que emergiam, principalmente nos países subdesenvolvidos ou em desenvolvimento economicamente. As ideias defendidas até então não encontravam, além de resistências às mudanças, os objetivos prometidos a partir de suas implementações. Dessa forma, na tentativa de articulação destes países que enfrentavam dificuldades em conjunto com estudiosos e representações de potências econômicas, ocorre em 1978 a Conferência de Alma Ata, na União das Repúblicas Socialistas Soviéticas (URSS), com a intencionalidade de tornar o setor saúde mais participativo e universalizante. Neste momento, a maior preocupação dos envolvidos era gerar propostas, conhecimentos e ferramentas que pudessem servir de alternativa ao modelo biomédico hegemônico. É a primeira vez em um espaço de cooperação internacional que a atenção primária em saúde aparece como uma prerrogativa para a organização dos serviços de saúde, sendo considerada como responsabilidade de cada governo para desenvolver ações em saúde que considerem os fatores sociais e econômicos em suas análises. A atenção primária deve ser organizada a partir de então para promover o primeiro contato do sujeito com o sistema de saúde de seu país (OHARA \& SAITO, 2014).

Porém, a realidade se mostrou de modo a dificultar essa implementação, principalmente nos países menos ricos. A crise econômica vivida pelos países, como o Brasil, menos desenvolvidos fez com que tivéssemos pouco proveito sobre as ideias definidas em Alma Ata. Mesmo com o avanço das ideias apresentadas, com o aprofundamento da crise, ficou difícil para os mais pobres manterem o compromisso com a dívida externa (com as grandes potências mundiais, como EUA) e repercutiu nas formas de implementação dos direcionamentos feitos na conferência: para termos uma ideia, as prerrogativas de participação popular, para executar controle sobre as finanças e organização dos serviços de saúde, e universalidade do acesso aos serviços não foram abarcadas pelas legislações destes países, sob a justificativa de representar uma dificuldade para a boa gestão em saúde e trazer morosidade às reformulações necessárias. Ou seja, via-se como risco às economias dos países essas duas mudanças por representarem, então, diminuição da autonomia do governo na gestão em saúde (é o caso do que ocorre no Brasil, como veremos a frente). 
Rev. Interd. em Cult. e Soc. (RICS), São Luís, v. 7, n. 2, p. 114- 135, jul./dez. 2021

ISSN eletrônico: $2447-6498$

Apesar deste parcial fracasso, muitas recomendações feitas em Alma Ata serviram de subsídios para a formulação de acordos de cooperação e projetos encabeçados pela OMS. Duas influências diretas podemos perceber: a) que a atenção primária em saúde (APS) deve se consolidar como o primeiro contato das pessoas com o sistema de saúde de seu país e b) este sistema deve fazer parte uma diretriz para o desenvolvimento econômico e social daquela nação. Sendo assim, mais uma vez com debates marcados pela preocupação econômica, estes serviços deveriam atuar, prioritariamente, para aquelas populações que não se caracterizam como em desenvolvimento econômico. É importante destacar a experiência do Canadá nesta conjuntura. Ainda em 1970, o Ministério da Saúde deste país apresenta sua ideia de promoção da saúde (através do documento A New Perspective on the Health of Canadians), assentada em elementos políticos, econômicos e sociais locais, com o objetivo principal de diminuir os gastos em saúde, majoritariamente impulsionados com serviços de diagnósticos e medicamentos com valores elevados de custos para confecção, conservação e distribuição. Para além, este documento apresenta críticas contundentes ao modelo biomédico, que estava muito mais preocupado com a doença e apresentava resultados duvidosos de suas intervenções (OHARA \& SAITO, 2014).

\footnotetext{
Esse documento estabeleceu o conceito de campo da saúde, reunindo os chamados determinantes da saúde, com a divisão "do campo da saúde em quatro amplos componentes: biologia humana, ambiente, estilo de vida e organização da assistência à saúde, dentro dos quais se distribuem inúmeros fatores que influenciam a saúde" (BUSS, 2000, p. 167). Carvalho (2004a) mostra que, se por um lado, as abordagens derivadas de La Londe foram responsáveis pela melhoria da qualidade de alguns grupos sociais, por outro tiveram um efeito menor ou mesmo negativo por parte de setores marginalizados. A partir dessa perspectiva, pode ser vista uma higiomania e corpolatria, quando o estilo de vida e hábitos pessoais passaram a ser foco principal das ações de promoção da saúde, gerando práticas disciplinares, criticadas pela ênfase em intervenções behavioristas desviadas da complexidade do fenômeno da saúde, derivando culpabilizações das vítimas (LOPES, 2012, p. 70).
}

Somente em 1984, a OMS passa, oficialmente, a utilizar o conceito de promoção da saúde, pois considera que este conceito envolve a população de forma mais abrangente, considerando sua complexidade, sem focar em grupos de riscos ou doenças a partir de elementos epidemiológicos. A adesão maior à promoção da saúde ocorre a partir de 1986 na Conferência de Ottawa, no Canadá. Este espaço ocorre exatamente no momento da constatação de diversos líderes e estudiosos de que o modelo preventivista não apresentava qualquer resposta satisfatória aos problemas de 
Rev. Interd. em Cult. e Soc. (RICS), São Luís, v. 7, n. 2, p. 114- 135, jul./dez. 2021

ISSN eletrônico: $2447-6498$

saúde enfrentados pelos países, mantendo índices alarmantes apesar do avanço nas discussões. Por outro lado, ressurgiam as compreensões do final do século XIX de que as epidemias e problemas de saúde resultantes seriam solucionados ao passo que se modificassem as condições de vida das populações. A isso, já no final do século XX, passou a ser reconhecido como epidemiologia social (ALMEIDA FILHO, 2011).

Com a Carta de Ottawa, a promoção da saúde deve ser responsabilidade do Estado, tendo que articular, além dos serviços do setor saúde, ações organizadas que envolvam o governo, organizações diversas, autoridades, espaços de produção e a mídia para facilitar a propagação das ideias. As condições de vida passam a ser reveladas como primordiais para a manutenção da qualidade de vida. Preocupações com moradia, saúde, educação, meio ambiente, devem nortear as ações dos governos na promoção da saúde, especialmente os serviços do nível primário, para que promovam intersetorialidade das políticas, equidade, participação e capacitação da população (ALMEIDA FILHO, 2011).

A Conferência de Ottawa foi, e ainda é, muito importante. Todas as resoluções, acordos, organizações que se sucederam após esta, tiveram influência demarcada pelo aprofundamento das discussões em tal redirecionamento da promoção da saúde. Outros eventos vindouros apresentaram ideias em concordância com a proposta de promoção da saúde (II Conferência Internacional sobre Promoção da Saúde, realizada na Austrália, em 1988 e a III Conferência Internacional sobre Promoção da Saúde, na Suécia, em 1991). Outro espaço relevante foi IV Conferência Internacional de Promoção da Saúde, na Indonésia (em 1997), pois constituiu sete importantes princípios para o planejamento e desenvolvimento da promoção da saúde, que são: a) compreensão holística em saúde, compreendo agora o ser humano como uma totalidade e fruto da sua relação com a realidade, para além dos aspectos biológicos somente; b) intersetorialidade, compreendendo que as políticas de saúde devem estar sincronizadas com as demais áreas que afetam-na; c) empoderamento, na perspectiva de garantir autonomia das pessoas em cuidados e capacidade de refletir e intervir sobre sua própria realidade; d) participação social, a fim de garantir a intervenção decisória das pessoas nos serviços de saúde; e) equidade, onde se garante a atenção à saúde da pessoa de acordo com suas características e idiossincrasias; f) ações multi-estratégicas, envolvendo diversas frentes de atuação de serviços distintos; e g) sustentabilidade, para garantir menos gastos, menos desperdícios (ALMEIDA FILHO, 2011). 
Rev. Interd. em Cult. e Soc. (RICS), São Luís, v. 7, n. 2, p. 114- 135, jul./dez. 2021 ISSN eletrônico: 2447-6498

As discussões realizadas nos diversos espaços internacionais de saúde foram aprimorando conceitos para poderem ser executados pelos Estados, tendo significado um importante avanço para o consenso das ideias de das formulações para a interferência sobre as condições e qualidade de vida das populações. Entretanto, vários discursos, sob o mesmo manto da promoção da saúde, tentaram se validar como pertencentes a este escopo, principalmente relacionados à educação em saúde, pois apresenta divergências importantes que podem impactar, por exemplo, na compreensão de empoderamento, uma vez que revela poderes em atrito e que impactam nas ações em saúde, assim como no desenvolvimento de autocuidado (ALMEIDA FILHO, 2011).

Ainda em concomitância aos desdobramentos advindos das discussões sobre promoção da saúde, muitos países passaram a adotar uma concepção de saúde ampliada, para além do modelo preventivista de outrora, mas ainda vigente em outras localidades, por mais que norteada pelo modelo flexneriano. Entretanto, o Banco Internacional para Reconstrução e Desenvolvimento (BIRD), em 1990, desenvolve movimentações para reorganizar a agenda mundial de políticas de saúde com projetos de ajustes estruturais, principalmente com avaliação da relação entre o custo de uma política e seu resultado, ou seja, índice de efetividade. Essa movimentação internacional inaugura uma racionalização, influenciada por uma lógica de financeirização da saúde. No documento "Investindo em saúde", por exemplo, o BIRD aponta mudanças que trariam impactos sobre o aumento da concentração de riquezas nos países de economia hegemônica, proporcionando concentração de riquezas por uma parcela minoritária da população e total desarticulação das políticas públicas nos países mais pobres (LUZ, 2007).

Outro acontecimento relevante que coaduna com as ações desenvolvidas pelo BIRD, foi o Consenso de Washington (que abordaremos mais à frente), em 1989, que já apontavam medidas que os Estados menos desenvolvidos deveriam seguir, sob o pretenso discurso de serem fórmulas que iriam retirar as economias da situação de crise que já viviam e iriam se aprofundar nos anos 1990. O alinhamento promovido pelo neoliberalismo em ascenso (tanto pelo BIRD, quanto pelo Consenso de Washington que funcionaram como catalisadores de sua expansão) fez com que economias latinas, por exemplo, reestruturassem suas políticas sociais, ainda que ocorresse o "esforço" de garantir o equilíbrio dessas economias, apresentando como resultado muito aquém do esperado (BATISTA JR, 2009). 
Rev. Interd. em Cult. e Soc. (RICS), São Luís, v. 7, n. 2, p. 114- 135, jul./dez. 2021

ISSN eletrônico: $2447-6498$

\section{CONSIDERAÇÕES FINAIS}

Essas mudanças refletem, por um lado, um avanço nas pautas democráticas por priorizar a atenção sobre as condições de vida dos sujeitos e possibilitar suas atuações, principalmente na saúde, já que historicamente, como vimos, é um espaço de pouca possibilidade até então, por outro, um avanço de uma política neoliberal, individualizante, marcadamente regulatória e vigilante sobre os corpos. Sendo assim, apesar de avançar em diversos aspectos e espaços institucionais, o debate de promoção da saúde estava refletindo, já no fim do século XX e início do século XXI, um dissenso da compreensão do seu próprio significado (podemos demarcar que de forma intencional, como explicado), mas em franca expansão de suas práticas, pouco delimitadas, em consequência da também não limitada compreensão e consenso. Essas divergências ocorrem principalmente por não haver uma coadunação sobre os limites entre prevenção e promoção da saúde, e assim, ainda encontramos o modelo de saúde hegemônico operando quando a promoção de saúde passa a ser medicalizada, ou seja, passa a ser uma política higienista, com conteúdo moral e buscando manter uma qualidade de vida para não diminuir a produção, para não afetar o trabalho, a fim de garantir o acúmulo de riqueza, a produção e o consumo (BATISTA JR, 2009).

Não há, com isso, a intenção de dizer que os conhecimentos produzidos até então sejam inválidos. As reorganizações dos serviços de saúde, assim como das práticas profissionais, foram enormemente afetadas por estas movimentações internacionais. Porém, vale destacar que atenção deva ser redobrada para que estas alterações não perpetuem práticas medicalizantes, como já vem ocorrendo. O problema da indefinição de promoção da saúde nos revela o antigo problema da indefinição do que viria ser saúde, com destaque para a atenção dada aos aspectos econômicos, sociais e culturais que passaram a ser considerados como fatores analíticos, ressaltando a necessidade de políticas intersetoriais. Por isso, Ferreira Neto (2009) nos alerta que as práticas de promoção com o fortalecimento da participação social e emancipação das pessoas apresenta aspecto positivo para a saúde, entretanto, denota as regulações e disciplinas oriundas desta mesma ferramenta, consolidando um poder político sobre a vida (biopolítica) e consequente medicalização.

\section{REFERÊNCIAS}


Rev. Interd. em Cult. e Soc. (RICS), São Luís, v. 7, n. 2, p. 114- 135, jul./dez. 2021

ISSN eletrônico: $2447-6498$

BAHIA, L. A privatização no sistema de saúde brasileiro nos anos 2000: tendências e justificação. In: SANTOS, N.; AMARANTE, P. (orgs.). Gestão Pública e Relação Público Privado na Saúde. Rio de Janeiro, Cebes, 2011.

BATISTA JÚNIOR, Francisco. Fundação estatal não fortalece o SUS. Disponível em: <http://www.cntsscut.org.br/download/funcacao-estatal-batista.pdf >. Acesso em: 20 out. 2009.

BERT, J. Pensar com Michel Foucault. São Paulo, Parábola, 2013.

BRANCO, G. C. Michel Foucault: filosofia e biopolítica. Belo Horizonte, Autêntica editora, 2015.

BRASIL. Constituição (1988). Capítulo II. Art. 196 a 200. Texto constitucional de 05 de outubro de 1988. Brasília, 1988.

Lei Orgânica da Saúde. Lei 8.080/90, de 19 de setembro de 1990. Dispõe sobre as condições para a promoção, proteção e recuperação da saúde, a organização e o funcionamento dos serviços correspondentes, e dá outras providências. Brasília. Presidência da República, 1990.

Ministério da Saúde, Ministério do Planejamento, Orçamento e Gestão.

Fundação Estatal; metas, gestão profissional e direitos preservados / Ministério da Saúde, Ministério do Planejamento, Orçamento e Gestão. Brasília, Ministério da Saúde, 2007.

CANABRAVA FILHO, Paulo. América Latina pós Consenso de Washington: Compondo uma nova Cultura. Disponível em:

<http://www.novasociedade.com.br/conjuntura/arquivos/conjuntura03.pdf > . Acesso em: 22 abr. 2010.

CANGUIlHEM, G. O normal e o patológico. Rio de Janeiro, Forense Universitária, 1995.

CARDOSO JÚNIOR, H. R.; LEMOS, F. C. S. (orgs.). Foucault e Deleuze/Guatarri: corpos, instituições e subjetividades. São Paulo, Annablume; Fapesp, 2011.

CLEMENTE, B. T. Cronologia histórica dos hospitais universitários. Salvador, 1998.

DALLARI, Dalmo de Abreu. Fundações estatais: proposta polêmica. In: Rev. Direito Sanit., São Paulo, v. 10, n. 1, jul. 2009.

DANNER, L., F. O caso da sociedade civil e de seus movimentos: sobre a perda de efetividade da cidadania política nas democracias ocidentais. Philósophos - Revista de Filosofia 15 (2):103-127. 2010.

DELEUZE, G.; GUATTARI, F. O anti-édipo: capitalismo e esquizofrenia 1. São Paulo, editora 34, 2011. 
Rev. Interd. em Cult. e Soc. (RICS), São Luís, v. 7, n. 2, p. 114- 135, jul./dez. 2021 ISSN eletrônico: $2447-6498$

DI PIETRO, Maria Sylvia Zanella. Parcerias na Administração Pública: concessão, permissão, franquia, terceirização e outras formas. $4^{\mathrm{a}}$ edição, São Paulo, Atlas, 2003.

DREYFUS, H.; RABINOW, P. Michel Foucault: uma trajetória filosófica: para além do estruturalismo e da hermenêutica. Rio de Janeiro, Forense universitária, 2013.

DUTRA, J.S.; FISHER, A.L.; AMORIN, W.A. C. (Org.). Gestão de Pessoas: desafios estratégicos das organizações contemporânea. São Paulo, Atlas, 2009.

FAÉ, R. A Genealogia em Foucault. Psicologia e Estudos, Vol. 9, n 3, Maringá, Setembro-Dezembro, 2004. Disponível em:

<http://www.scielo.br/scielo.php?script=sci_arttext\&pid=S1413-73722004000300009>. Acesso em: 15 out. 2013.

FAUSTO, B. História Concisa do Brasil. 2 ed. São Paulo, editora da Universidade de São Paulo, 2014.

FLEURY, S. Reforma sanitária brasileira: dilemas entre o instituinte e o instituído. Ciência \& Saúde Coletiva, 14(3):743-752, 2009

FLEURY, S.; BAHIA, L.; AMARANTE, P. Saúde em debate: Fundamentos da Reforma Sanitária. Rio de Janeiro, Cebes, 2008.

FOUCAULT, M. A coragem da verdade: o governo de si e dos outros II: curso no Collège de France (1983-1984). São Paulo, editora WMF Martins Fontes, 2011.

A ordem do discurso: aula inaugural do Collége de France, pronunciada em 2 de dezembro de 1970. São Paulo, edições Loyola, 2014.

A arqueologia do saber. Rio de Janeiro, Forense universitária, 2005.

. Ditos e escritos, volume IV: estratégia, poder-saber. Rio de Janeiro, Forense universitária, 2012.

Ditos e escritos, volume VI: repensar a política. Rio de Janeiro, Forense universitária, 2013.

Em defesa da sociedade: curso no Collège de France (1975-1976). 2 ed. São Paulo: editora WMF Martins Fontes, 2010.

. História da Sexualidade 1: a vontade de saber. $2^{\text {a }}$ Ed. São Paulo, Paz e terra, 2015. Paulo, Graal, 2013.

Microfísica do poder. Org. e Trad.: Roberto Machado. $27^{a}$.Ed. São

O governo de si e dos outros: curso no Collège de France (1982-

1983). São Paulo, editora WMF Martins Fontes, 2010. 
Rev. Interd. em Cult. e Soc. (RICS), São Luís, v. 7, n. 2, p. 114- 135, jul./dez. 2021

ISSN eletrônico: $2447-6498$

. O nascimento da biopolítica. Lisboa, edições 70, 2010.

. Segurança, território e população. São Paulo, Martins Fontes, 2008.

GALVÃO, A. et al. (orgs.). Capitalismo: crises e resistências. São Paulo, outras expressões, 2012.

GRUBITS, S.; NORIEGA, J. A. V. Método Qualitativo: epistemologia, complementariedades e campos de aplicação. São Paulo, Vetor, 2004.

LE GOFF, J. História e Memória. Editora UNICAMP, Campinas, 1990.

LEMOS, F. C. S. \& CARDOSO JR., H. R. A Genealogia em Foucault: uma trajetória. Psicologia e Sociedade, vol. 21, p. 353-357, n 3. Rio de Janeiro, 2009. Disponível em: <http://www.scielo.br/pdf/psoc/v21n3/a08v21n3.pdf>. Acesso em 15 out. 2013.

LEMOS, F. C. S. et al. Psicologia, educação, saúde e sociedade: transversalizando. Curitiba, CRV, 2015.

LEMOS, F. C. S. et al. Tranversalizando no ensino, na pesquisa e na extensão. Curitiba, CRV, 2012.

LEMOS, F. C. S. O controle da vida: práticas de conselheiros tutelares. Curitiba, Appris, 2015.

LEMOS, F. et al. "A Análise Documental como Instrumento Estratégico para Michel Foucault”. In: Itinerários de Pesquisa em Psicologia. PIMENTAL, A.; RODRIGUES, M.; NICOLAU, R. F.; LEMOS, F. C. S. (Orgs.). Belém: Amazônia Editora, 2010.

LIMA, B. J. M.; LIMA, A. M. As Fundações Estatais de Direito Privado e seus reflexos sobre o mundo do trabalho do Enfermeiro; orientadora: Elizabeth Lucena Rodrigues. Trabalho de Conclusão de Curso. UEPA. 2010.

LIMA, Bruno Jáy Mercês de. A Empresa Brasileira de Serviços Hospitalares (EBSERH) e suas ressonâncias sobre os hospitais universitários: uma análise documental histórico-genealógica sobre a lei 12.550/2011. Universidade Federal do Pará. Belém, 2013. Orientador: Profa ${ }^{a}$ Dr ${ }^{a}$. Flávia Cristina Silveira Lemos.

LOBO, L., PRADO FILHO, K. \& LEMOS, F. C. S. Alguns Aspectos da Pesquisa Documental nos Estudos Históricos de Michel Foucault.

LOURAU, R. A análise institucional. Petrópolis, RJ, Vozes. 1995.

LOURAU, R. Análise Institucional e Práticas de Pesquisa. Rio de Janeiro, NAPE/UERJ, 1993.

LUZ, Madel Therezinha. Notas sobre as políticas de saúde no Brasil de "transição democrática" - anos 80. PHYSIS - Revista de Saúde Coletiva, São Paulo, v.1, n.1. 1991. 
Rev. Interd. em Cult. e Soc. (RICS), São Luís, v. 7, n. 2, p. 114- 135, jul./dez. 2021

ISSN eletrônico: $2447-6498$

MENDES, Eugênio Vilaça. As políticas de saúde no Brasil nos anos 80: a conformação da reforma sanitária e a construção da hegemonia do projeto neoliberal. In: As políticas de saúde no Brasil nos anos 80. Brasília, nov. 1991. p 19-91.

MENICUCCI, T. Público e privado na política de assistência à saúde no Brasil: atores, processos e trajetórias. Rio de Janeiro, editora FIOCRUZ, 2007.

MOTAÑO, C. (org.). O canto da sereia: crítica à ideologia e aos projetos do "terceiro setor”. São Paulo, Cortez, 2014.

NAIM, Moisés. Ascenção e Queda do Consenso de Washington: O Consenso de Washington ou a Confusão de Washington? In: Revista Brasileira de Comércio Exterior. Disponível em: <http://www.funcex.com.br/bases/64-

Consenso\%20de\%20Wash-MN. PDF>. Acesso em: 22 abr. 2010.

NORONHA, José Carvalho de; SOARES, Laura Tavares. A política de saúde no Brasil nos anos 90. Ciência \& Saúde Coletiva, v. 6, nº 2, p.445-450, 2001.

PASSOS, E.; KASTRUP, V.; ESCÓSSIA, L. (ORGS.). Pistas do método da cartografia: Pesquisa-intervenção e produção de subjetividade. Porto Alegre, Sulina, 2015 .

PAULON, S. A análise de implicação como ferramenta na pesquisa-intervenção. Psicologia \& Sociedade, 17 (3), 18-25, set-dez: 2005.

PIMENTEL, A.; LEMOS, F.; SOUZA, M.; NICOLAU, R. (orgs.). Itinerários de pesquisas em psicologia. Belém, Amazônia editora, 2010.

PINSKY, C. (org.). Fontes históricas. São Paulo, Contexto, 2014.

SANT'HELENA, M.M. et al. Da Reforma Sanitária às Privatizações: discutindo a saúde pública brasileira. Congresso Catarinense de Assistentes Sociais. Florianópolis, 2013.

SCHWARCZ, L. M.; STARLING, H. M. Brasil: uma biografia. São Paulo, Companhia das letras, 2015.

SEVERINO, A. J. Metodologia do trabalho científico. 23 ed. São Paulo, Cortez, 2007.

SOUZA, M. R.; OLIVEIRA, P. T. R.; PIANI, P. P. F. (orgs.). Psicologia: políticas, formação, profissão e pesquisa. Belém, Para-Tatu, 2012.

VEYNE, P. Como se escreve a história. Trad. Alda Baltar e Maria Auxiliadora Kneipp. 4. ed. Brasília, UnB, 1998.

ZAMBENEDETTI, G. \& Silva, R. A. N. Cartografia e genealogia: aproximações possíveis para a pesquisa em psicologia social. In: Psicologia \& Sociedade, Rio Grande do Sul, v. 23, n. 3, p. 454-463, jul. 2011. 